\title{
PENGARUH PENAMBAHAN TURBO CYCLONE AKSIAL TERHADAP ALIRAN DAN PERFORMA MOTOR BAKAR
}

\author{
Yusuf Rizal Fauzi \\ Jurusan Teknik Mesin, Politeknik Kotabaru \\ Jalan raya Stagen, K.M. 9,5. Kotabaru, Kalimantan Selatan, Indonesia \\ Email: rizal.fauzi@engineer.com
}

\begin{abstract}
Complete combustion is a process that is expected in a burning, this can be achieved when a mixture of fuel and air evenly and fairly homogeneously distributed in the engine cylinder. This research aims to determine the effect of the flow and performance of the Honda GL PRO motorcycles with a cylinder capacity of $156 \mathrm{cc}$. This test is done to determine the effect of pre-combustion and post-combustion engine using turbo cyclone and the flow passing through the carburetor. This method uses fluent 6.2 software and statistical tests. With the use of axial turbo cyclone, it can improve the performance of gasoline engine with swirl flow obtaining fuel-air mixture better and get the desired performance. The results obtained from testing Effective Power by using turbo cyclone is $0.7239654 \mathrm{HP}$ average, and $0.4151938 \mathrm{HP}$ average without turbo cyclone. Torque by using turbo cyclone $0.2592512 \mathrm{~kg} . \mathrm{m}$ average, and $0.1486808 \mathrm{~kg} . \mathrm{m}$ average without turbo cyclone, the value of Effective Fuel Consumption by using turbo cyclone is $0.325596 \mathrm{~kg} / \mathrm{HP}$.hour average and $0.9273914 \mathrm{~kg} / \mathrm{HP}$.hour average without turbo cyclone. Efficiency Thermic Effective ( $\eta$ e) by using turbo cyclone is 14.1434058 $\%$ average and $6.229145 \%$ average without turbo cyclone.
\end{abstract}

Keywords: Turbo cyclone, performance, and flow.

\section{PENDAHULUAN}

Pembakaran sempurna merupakan proses yang sangat diharapkan pada suatu pembakaran, hal ini bisa tercapai apabila campuran bahan bakar dan udara terdistribusi merata dan cukup homogen didalam silinder engine. Dengan adanya aliran swirl ini mixing akan lebih sempurna karena disamping mempunyai kesempatan waktu lebih lama untuk bercampur juga bentuk swirl itu sendiri yang memudahkan bahan bakar dan udara untuk bercampur.

Penelitian mengenai turbo cyclone jenis radial terhadap performance mesin kijang pernah dilakukan [1], dimana penambahan turbo cyclone menyebabkan daya meningkat dan konsumsi bahan bakar menurun untuk putaran diatas 3500 rpm. Sedangkan efisiensi termis meningkat untuk putaran tinggi. Eksperimen tentang turbo cylone jenis radial juga pernah dilakukan [2] dengan menggunakan wintanel, dimana turbo cyclone dengan sudut pengarah $60^{\circ}$ mempunyai vortex strength yang lebih kuat dibanding sudut pengarah $45^{\circ}$. Setelah itu muncul lagi penelitian turbo cyclone jenis aksial dengan bentuk pejal yang diletakan setelah karburator [3] juga menggunakan wintanel. Dimana hasil yang didapatkan adalah, aliran setelah melewati peralatan ini menjadi terpelintir dengan kecepatan terbesar memusat di tengah.Dengan menggunakan wintanel yang sama, namun menggunakan model turbo cyclone aksial yang berbeda, yaitu tidak lagi pejal melainkan menggunakan sudu-sudu, [4] juga melakukan penelitian. Hasilnya bahwa turbo cyclone dengan bentuk sudu lengkung memberikan intensitas swirl lebih tahan lama/berelaksasi lebih lama, ditunjukkan dengan variasi tekanan yang lebih besar untuk jarak yang sama dengan Turbo cyclone jenis pejal.

Banyaknya penelitian tentang turbo cyclone memunculkan ide meneliti tentang pengaruh penambahan turbo cyclone aksial 
yang diletakkan sebelum karburator, mengingat dengan terbentuknya aliran swirl ketika melewati karburator membuat udara dan bahan bakar dapat bercampur lebih homogen.

Untuk pemakaian axial turbo cyclone secara luas karena dapat meningkatkan unjuk kerja mesin motor bakar bensin dengan memperoleh aliran swirl campuran bahan bakar udara yang lebih baik dan mendapatkan performance yang di inginkan.

\section{TINJAUAN PUSTAKA}

\section{Turbo Cyclone}

Turbo Cyclone merupakan suatu alat yang terbuat dari logam stainless steel yang mempunyai beberapa sirip/sudu dengan sudut kemiringan tertentu terhadap sumbu tegaknya dipasang pada saluran udara sebelum karburator yang berfungsi untuk mengarahkan udara yang masuk ke karburator, menjadi berbentuk swirl (terpelintir). Hal ini terjadi sebagai akibat pembelokan udara secara paksa oleh adanya sudu - sudu miring dengan sudut tertentu saat melewati turbo cyclone.

\section{Pengaruh Pemasangan Turbo Cyclone Pada Mesin}

Dari penelitian yang telah dilakukan oleh Rudi Rubiantoro [1] pada tugas akhirnya, dapat diketahui bahwa dengan pemasangan Turbo Cyclone jenis radial pada motor empat langkah akan memberikan beberapa efek pada motor yaitu:

- Pada putaran motor antara 1500 - 3500 rpm (putaran rendah sampai pada putaran menengah) dengan penambahan turbo cyclone justru akan menurunkan daya dari mesin, tetapi pada putaran menengah keatas yaitu $3500 \mathrm{rpm}$ lebih, penambahan turbo cyclone akan menaikkan daya dari mesin apabila dibandingkan dengan tanpa TC.

- Analisa pada sfe dapat diketahui bahwa dengan penambahan TC pada putaran rendah akan menaikkan sfc tetapi pada putaran yang tinggi penambahan TC akan menurunkan sfc yang berarti konsumsi bahan bakar menjadi lebih sedikit (irit). Hal ini terjadi karena pada putaran motor tinggi aliran udara yang membentuk swirl menjadi lebih sempurna dan kuat sehingga dapat menghambat laju semprotan bahan bakar dari nozzel.

- Demikian juga dengan efisiansi thermis, dimana dengan penambaha TC pada putaran rendah, effisiensi thermis rendah dengan penambahan TC tetapi pada putaran tinggi effisiensi thermis akan tinggi dengan pemasangan TC.

\section{Sifat Fisik Aliran Laminer dan Turbulen}

Aliran internal dan viscous (laminer atau turbulen) ditentukan oleh harga Reynold yang perbedaaanya secara kualitatif di demonstrasikan oleh eksperimen Osborne Reynold, pada eksperimen tersebut, air dari reservoir dialirkan melalui saluran yang transparan. Pada bagian intrence saluran, diinjeksikan filamen tinta tipis untuk mengamati aliran secara visual.

Pada laju aliran yang rendah (angka Reynold kecil), tinta yang diinjeksikan kedalam aliran membentuk filamen tunggal yang membentuk garis lurus. Tinta tidak mengalami dispersi karena aliran adalah laminer. Pada aliran yang laminer, fluida mengalir pada lapisan (layer) tertentu dan tidak terjadi pertukaran (mixing) secara makroskopik diantara lapisan-lapisan fluida yang berdekatan.

Apabila laju aliran ditingkatkan, filamen tinta menjadi tidak stbil dan berubah menjadi gerak acak. Garis yang dibentuk oleh filamen tinta menjadi seperti benang kusut, dan kondisi ini dengan cepat menyebar ke seluruh medan aliran. Pertukaran partikel fluida diantara lapisan yang berdekatan, menyebabkan tinta terdispersi dengan cepat. Perilaku aliran turbulen ini mengarah ke fluktuasi kecepatan, sehingga analisa aliran turbulen didasarkan pada gerak rata-rata aliran. 
Secara kuantitatif, perbedaan antara aliran laminer dan turbulen bisa diketahui dengan menempatkan alat ukur kecepatan yang sensitif pada medan aliran. Apabila dilakukan pengukuran terhadap komponen kecepatan (misal dalam arah $\mathrm{x}$ ), maka untuk aliran steady laminer dan turbulen akan diperoleh variasi kecepatan terhadap waktu. Untuk aliran laminer steady, kecepatan di satu titik tertentu tetap konstan terhadap perubahan waktu, sedangkan untuk aliran turbulen, grafik kecepatan menunjukkan bahwa kecepatan sesaat untuk, berfluktuasi secara acak.

\section{Prinsip Kerja Motor Empat Langkah.}

Proses pembakaran di dalam motor bakar terjadi secara periodik. Di dalam motor empat langkah dalam satu siklus terjadi empat kali langkah torak.Adapun prinsip kerja motor empat langkah adalah sebagai berikut :

1. Langkah Isap (Intake Sroke)

Langkah isap adalah torak bergerak dati TMA (titik mati atas) ke TMB (titik mati bawah) yang mana pada saat tersebut katup isap terbuka dan katup buang tertutup. Campuran bahan bakar dan udara terhisap dan mengalir melalui katup isap ke dalam silinder.

2. Langkah Kompresi (Compresion Stroke)

Torak bergerak dari TMB ke TMA untuk memampatkan campuran bahan bakar dan udara, dimana katup isap dan katup buang tertutup. Campuran bahan bakar dan udara yang terhisap tadi terkurung didalam silinder dan dimampatkan oleh torak yang bergerak ke TMA. Volume campuran bahan bakar dan udara itu menjadi kecil dan karena itu tekanan dan temperaturnya naik hingga campuran itu mudah sekali terbakar.

3. Langkah Kerja (Power Stroke)

Pada saat torak hampir mencapai TMA campuran bahan bakar dan udara segar itu dinyalakan, terjadilah proses pembakaran sehingga tekanan dan temperaturnya naik. Sementara itu torak masih bergerak menuju TMA, berarti volume ruang bakar menjadi semakin kecil sehingga tekanan dan temperature gas di dalam silinder menjadi semakin tinggi. Akhirnya torak mencapai TMA dan gas pembakaran mampu mendorong torak untuk bergerak kembali dari TMA ke TMB. Sementara itu katup isap maupun katup buang masih tertutup selama torak bergerak dari TMA ke TMB.

4. Langkah Buang (Exhaust Stroke)

Saat torak hampir mencapai TMB katup buang sudah terbuka sedangkan katup isap tertutup. Torak bergerak kembali ke TMA mendesak gas hasil pembakaran keluar dari dalam silinder melalui saluran buang.
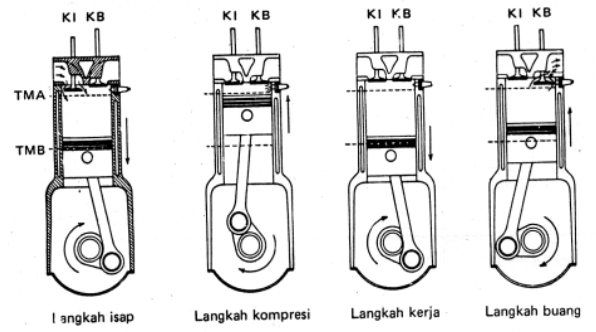

Gambar 1. Prinsip Kerja Motor 4 (Empat) Langkah

\section{Motor Dua Langkah}

Motor dua tak adalah motor bakar dimana dalam satu proses pembakaran di dalam silinder memerlukan dua langkah kerja. Adapun konstruksi motor dua tak ini amat sederhana jika dibandingkan dengan motor empat tak.

Pada motor dua tak, untuk mencapai satu siklus kerjanya membutuhkan dua langkah gerakan piston atau satu putaran poros engkol. Siklus adalah rangkaian peristiwa yang selalu berulang kembali mengikuti jejak yang sama seperti semula dan membentuk rangkaian tertutup.

Konstruksi motor dua langkah lebih sederhana, semua pembukaan dan penutupan lubang hisap dan lubang buang dilakukan oleh toraknya sendiri. Oleh karena itu, bobot setiap satuan daya yang dihasilkan menjadi kecil. 


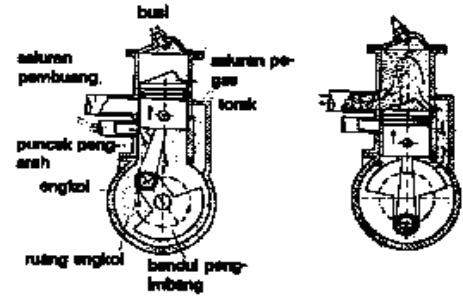

Gambar 2. Rangkaian Siklus Motor Dua langkah

\section{METODE PENELITIAN}

Penelitian menggunakan sistem sofware Fluent 6.2 untuk mengetahui kecepatan aliran dan kontur tekanan yang masuk ke turbo cyclone dan uji statistik.

\section{Tempat Penelitian}

Proses pengumpulan data dalam penelitian ini dilakukan di Laboratorium Balai Latihan Kerja Banjarmasin, Kalimantan Selatan.

\section{Alat dan Bahan}

Alat dan bahan yang digunakan pada eksperimen ini sebagai berikut:

1. Satu unit mesin Honda GL PRO 156CC

2. Satu unit turbo cyclone sudu 8 .

3. Bahan bakar, dalam hal ini adalah bensin atau premium

4. Stop watch, untuk mengukur waktu dalam eksperimen

5. Tachometer Digital untuk mengukur putaran mesin.

6. Laptop untuk menjalankan sofware fluent 6.2

\section{Prosedur Penelitian}

Prosedur atau langkah-langkah dalam pelaksanaan penelitian adalah sebagai berikut ini:

\section{Memilih masalah}

Pengambilan masalah ini didasarkan pada survey awal dari pemakai sepeda motor Honda GL pro $156 \mathrm{cc}$ yang di pasang turbo cyclone.

\section{Studi Pendahuluan}

Studi pendahuluan dimaksudkan untuk mencari informasi yang diperlukan agar masalah lebih jelas kedudukannya. Studi pendahuluan memuat informasi tentang turbo cyclone, bagaimana pengaruh pemasangan turbo cyclone.

\section{Pelaksanaan eksperimen}

Pelaksanaan eksperimen dibagi menjadi dua tahap, yaitu:

a. Persiapan eksperimen, yang meliputi:

1) Memastikan mesin dalam kondisi normal dan memeriksa peralatan yang akan digunakan dalam penelitian.

2) Menyiapkan kendaraan atau mesin yang akan digunakan untuk penelitian, yang meliputi :

3) Mempersiapkan turbo cyclone yang akan digunakan dalam pengujian. Melakukan pengujian dengan sepeda motor tanpa turbo cyclone untuk mengetahui kecepatan aliran dan volt, ampere dan konsumsi bahan bakar.

4) Melakukan pemasangan turbo cyclone pada sepeda motor Honda GL pro. Mengetahui kecepatan aliran, volt, ampere, dan konsumsi bahan bakar.

b. Pelaksanaan Eksperimen

Mencari waktu konsumsi bahan bakar sebelum pemasangan turbo cyclone.Setelah mesin dihidupkan dan putaran mesin $2000 \mathrm{rpm}$, maka pengukuran jumlah bahan bakar yang terpakai dimulai dengan menggunakan stop watch, dalam menghabiskan bahan bakar $30 \mathrm{ml}$ sambil melihat bahan bakar yang ada dalam gelas ukur. Sejumlah bahan bakar $30 \mathrm{ml}$ akan dihabiskan dalam waktu tertentu. Mengukur waktu konsumsi bahan bakar mesin dengan pemasangan turbo cyclone.Setelah mesin dihidupkan dan putaran mesin 2000 rpm, pengukuran jumlah bahan bakar yang terpakai dimulai dengan menggunakan stop watch menghabiskan bahan bakar selama $30 \mathrm{ml}$ sambil melihat bahan bakar yang ada dalam gelas ukur, bahan bakar akan dihabiskan dalam waktu tertentu. Pengambilan data dilakukan kembali selama lima kali percobaan dengan putaran $2000 \mathrm{rpm}$. 
HASIL DAN PEMBAHASAN

\section{Perhitungan Data Standard}

\section{Daya efektif (Ne)}

$$
\begin{aligned}
& \mathrm{Ne}=\frac{(V . I) x \cos \theta}{0.736 .10^{2} x \eta_{g}} \\
& =\frac{(11.25 \times 2.06) x \cos 1}{0.736 .10^{2} x 0.8} \\
& =0.393597(\mathrm{PS}) \text { dimana } \\
& 1 \mathrm{PS}=0,9863 \mathrm{HP} \\
& 0.393597 \mathrm{PS}=0.388205 \mathrm{HP} \\
& 1 \mathrm{PS}=0,9863 \mathrm{HP}
\end{aligned}
$$

\section{Torsi (T)}

$$
\begin{aligned}
\mathrm{T} & =716,2 \times \frac{\mathrm{Ne}}{\mathrm{n}} \\
& =716.2 x \frac{0.388205}{2000} \\
& =0.139016 \mathrm{~kg} \cdot \mathrm{m}
\end{aligned}
$$

Keterangan :

$$
\begin{array}{ll}
\mathrm{Ne} & =\text { daya efektif }(\mathrm{Hp}) \\
\mathrm{T} & =\text { torsi }(\mathrm{kg} \cdot \mathrm{m}) \\
\mathrm{n} & =\text { putaran mesin }(\mathrm{Rpm})
\end{array}
$$

\section{Konsumsi Bahan Bakar Spesifik Efektif} (SFCe)

$$
\begin{aligned}
& \mathrm{SFCe}=\frac{\mathrm{FC}}{\mathrm{Ne}} \operatorname{dimana} \mathrm{FC}=\frac{\mathrm{b}}{\mathrm{t}} \times \gamma \mathrm{f}_{\frac{3600}{1000}} \\
& \begin{aligned}
\mathrm{FC}=\frac{30}{204} \times 0,74 \times \frac{3600}{1000} \\
=0,391 \mathrm{~kg} / \mathrm{jam}
\end{aligned} \\
& \mathrm{SFCe}=\frac{0.391}{0.388205}=1.00917 \mathrm{~kg} / \mathrm{HP} . \mathrm{jam}
\end{aligned}
$$

Keterangan :

SFCe = Konsumsi bahan bakar spesifik efektif (kg/Hp.jam)

Fc $\quad=$ Konsumsi bahan bakar (kg/jam)

$\mathrm{Ne} \quad=$ Daya efektif $(\mathrm{Hp})$

\section{Efisiensi Thermal Efektif $\left(\boldsymbol{\eta}_{\mathrm{e}}\right)$}

$\eta \mathrm{e}=\frac{\mathrm{Ne}}{\mathrm{Qb}} \times 632 \times 100 \%$ dimana $\mathrm{Qb}=\mathrm{FC}$ LHVbb

$$
\begin{aligned}
\mathrm{Qb} & =0,391 \times 11000 \\
& =4309.412 \mathrm{kcal} / \mathrm{jam}
\end{aligned}
$$

$$
\begin{aligned}
\eta e & =\frac{0.388205}{4309.412} \times 632 \times 100 \% \\
& =5.693247 \%
\end{aligned}
$$

Keterangan :

$\eta_{e} \quad=$ Efisiensi Thermal efektif

SFCe $=$ Spesifik Fuel Consumption

Efektif (kg/Hp.jam)

$\mathrm{LHV}_{\mathrm{bb}}=$ Nilai kalor bawah bahan bakar

$$
\text { (11000 kcal/kg) }
$$

\section{Pengaruh Penambahan Turbo Cyclone Pada Bentuk Aliran}

Untuk mengetahui pengaruh penambahan turbo cyclone aksial terhadap bentuk aliran yang melintasinya, dapat dilihat pada gambar dengan menggunakan media bantu serbuk tepung tampak bahwa, aliran yang yang melewati saluran pipa transparan akan mempunyai bentuk yang lurus selama tidak ada halangan yang mengganggunya. Tetapi ketika pada inlet saluran tersebut ditambahkan Turbo Cylone dengan sudu-sudu lengkungnya, maka akan membuat aliran yang melewatinya menjadi berputar mengikuti bentuk sudu pada Turbo Cylone seperti pada gambar.Hal ini dapat dijelaskan dengan menggunakan gambar di bawah, dimana pada saat aliran mulai masuk / melintasi sudu-sudu lengkung dengan kecepatan $\mathrm{V}_{1}$ aliran masih dalam keadaan lurus, tetapi ketika mulai melewati sudu maka mulai terjadi pembelokan aliran.

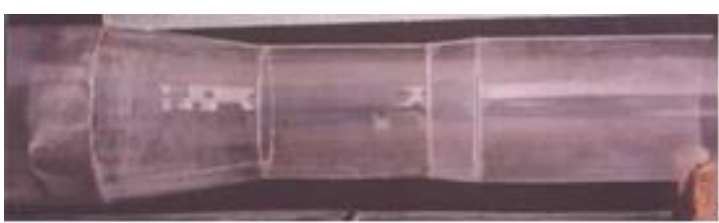

Gambar 3. Bentuk aliran Tanpa Turbo Cyclone

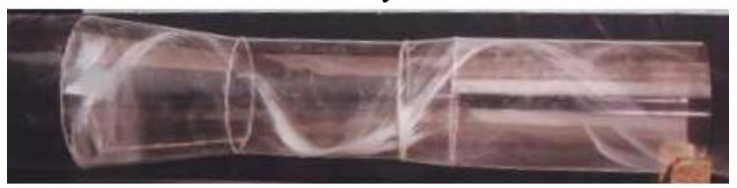

Gambar 4. Bentuk aliran Melewati Turbo Cyclone 
Grafik Perbandingan Daya Efektif (Hp)

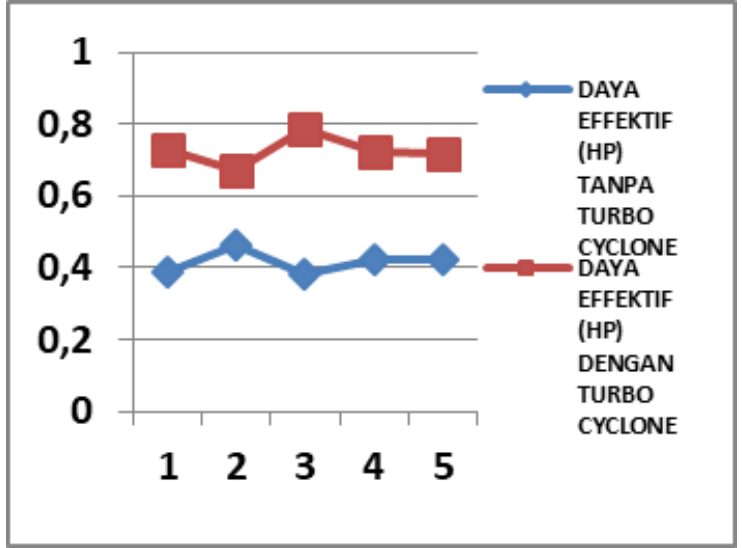

Gambar 5. Grafik Perbandingan Daya

\section{Efektif}

Dari grafik analisa data diperoleh hasil bahwa nilai Daya Effektif dengan mengunakan Turbo cyclone dan tanpa turbo cyclone yaitu rata-rata $0,7239654 \mathrm{HP}$ dan rata-rata 0,4151938 HP.

\section{Torsi (T)}

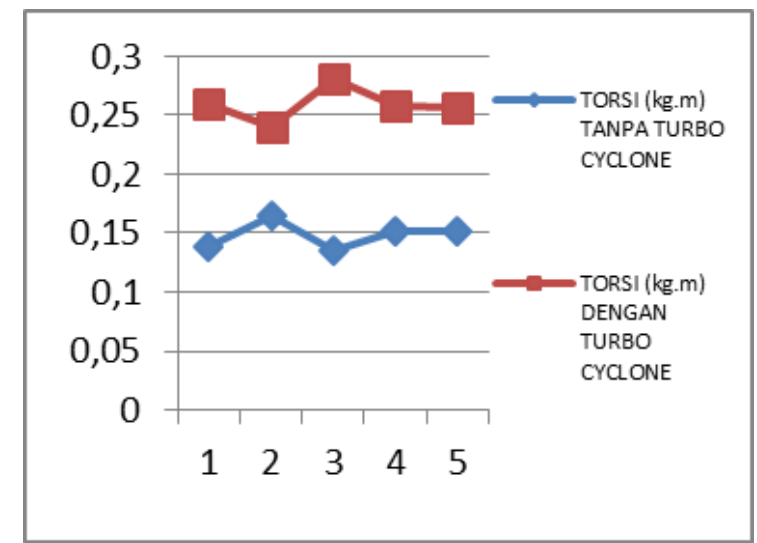

Gambar 6. Grafik Perbandingan Torsi

Dari grafik analisa data diperoleh hasil bahwa nilai Torsi dengan mengunakan Turbo cyclone dan tanpa turbo cyclone yaitu rata-rata 0,2592512 kg.m rata-rata 0,1486808 kg.m.
Grafik Perbandingan Konsumsi Bahan Bakar (SFCe)

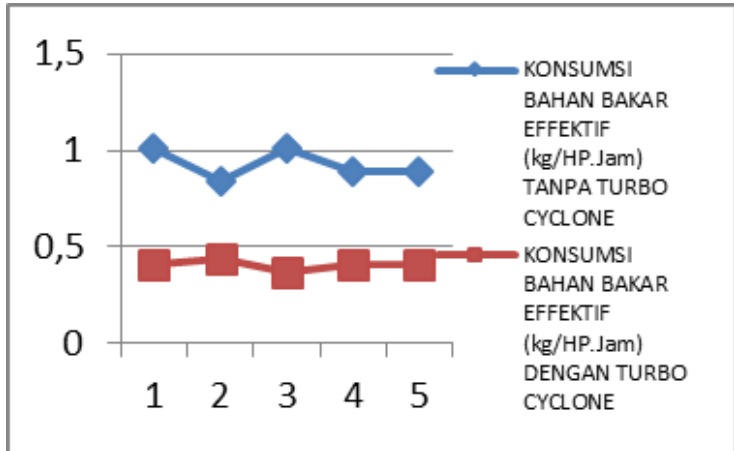

Gambar 7. Grafik Perbandingan Konsumsi Bahan Bakar

Dari grafik analisa data di peroleh hasil bahwa nilai Konsumsi Bahan Bakar Effektif (SFCe) dengan mengunakan Turbo cyclone dan tanpa turbo cyclone yaitu ratarata $0,325596 \mathrm{~kg} / \mathrm{HP}$.jam dan rata-rata 0,9273914 kg/HP.jam

\section{Grafik Perbandingan Efisiensi Thermis Efektif ( $\left.\eta_{e}\right)$}

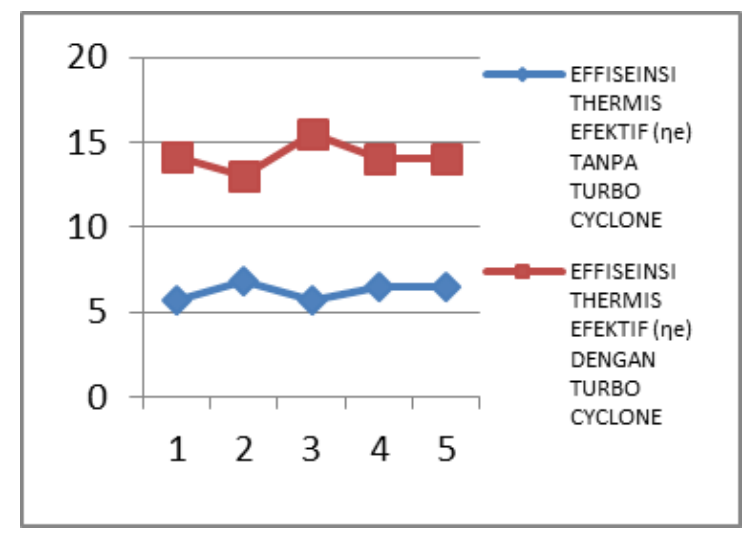

Gambar 8. Grafik Perbandingan Efisiensi Thermis Efektif

Dari grafik analisa data diperoleh hasil bahwa nilai Effiseinsi Thermis Effektif $\left(\eta_{\mathrm{e}}\right)$ dengan mengunakan Turbo cyclone dan tanpa turbo cyclone yaitu ratarata $14,1434058 \%$ rata-rata $6,229145 \%$.

\section{KESIMPULAN}

Dapat disimpulkan turbo cyclone aksial akan bertambah besar, karena terjadi penyempitan luasan pada outlet turbo cyclone akibat sudut chamber $\theta$, (TC sudu $6 \theta=70^{\circ}$; TC sudu $8, \theta=60^{\circ}$ ). Dengan menggunakan CFD Fluent 6.2. 
Terjadi perubahan dengan mengunakan Turbo cyclone dan tanpa turbo cyclone pada Daya efektif 0,7239654 $\mathrm{HP}$ dan rata-rata $0,4151938 \mathrm{HP}$, Torsi 0,2592512 kg.m dan 0,1486808 kg.m, Konsumsi bahan bakar 0,325596 kg/HP.jam dan 0,9273914 kg/HP.jam, Efisinsi thermis $14,1434058 \%$ dan $6,229145 \%$.

\section{REFERENSI}

[1]. Rudi Rubiantoro ,"Study Banding Unjuk Kerja dan Emisi Gas Buang dari Motor Bensin 4 Langkah terhadap Penambahan Peralatan Turbo Cyclone", Tugas Akhir Teknik Mesin FTI ITS, 1989.

[2]. Wisnu Satria I ,"Study eksperimental tentang karakteristik medan aliran tiga dimensi pada saluran outlet dari model internal flow cyclone (IFC)"Tugas akhir Teknik Mesin FTI ITS, 2001.

[3]. I'im Nurhadi ,'Study eksperimental tentang pengaruh penambahan turbo cyclone terhadap intensitas vortek pada saluran berpenampang sirkular dengan luasan konstan", Tugas Akhir Teknik Mesin FTI ITS, 1999.

[4]. Victor L. street and E. Benjamin Wyle," Fluid mechanic",sevent edition, new york: McGrawHill. 